\title{
MANIFESTAÇÕES DO RACISMO INSTITUCIONAL ERELIGIOSO EM COMUNIDADES QUILOMBOLAS NO MATO GROSSO DO SUL
}

\author{
Dyego de Oliveira Arruda (1) $\triangle$
}

Centro Federal de Educação Tecnológica Celso Suckow da Fonseca I Valença - RJ - Brasil

Milton Augusto Pasquotto Mariani (D)

Universidade Federal de Mato Grosso do Sul I Campo Grande - MS - Brasil

Gabriel Luis Pereira Nolasco (D) $ه$

Universidade Católica Dom Bosco I Campo Grande - MS - Brasil

Caroline Oliveira Santos (1) $\square$ 
Este artigo tem como objetivo compreender aspectos das dimensões institucional e religiosa do racismo que se manifesta em comunidades quilombolas no Mato Grosso do Sul, no Centro-Oeste brasileiro. Como estratégia metodológica, realizou-se uma pesquisa de abordagem qualitativa, na qual foram realizados processos de observação participante, diálogos e interações com quilombolas de sete comunidades localizadas no Mato Grosso do Sul. De um modo geral, foi possível constatar que as manifestações de racismo institucional e religioso fazem com que as comunidades quilombolas sejam espaços de significativa precariedade, nos quais os sujeitos aquilombados subsistem, sem que consigam acessar um conjunto de serviços públicos básicos, além de serem compulsoriamente impelidos a renunciar elementos de sua história, cultura e até de sua subjetividade. Sem a pretensão de esgotar a temática, o artigo traz, nas considerações finais, algumas problematizações que reforçam a necessidade do engajamento no combate às manifestações de racismo na sociedade contemporânea.

Palavras-chave: comunidades quilombolas; racismo institucional; racismo religioso; Mato Grosso do Sul.

\section{MANIFESTATIONS OF INSTITUTIONAL AND RELIGIOUS RACISM IN QUILOMBOLA COMMUNITIES IN MATO GROSSO DO SUL}

This paper aims to understand aspects of the institutional and religious dimensions of racism that is manifested in quilombola communities in Mato Grosso do Sul, in the Brazilian Midwest. As a methodological strategy, a qualitative research was carried out, in which participatory observation processes, dialogues and interactions were made with subjects from seven quilombolas communities located in Mato Grosso do Sul. In general, we found that the manifestations of institutional and religious racism make quilombola communities spaces of significant precariousness, in which the quilombolas individuals subsist without being able to access the basic public services, in addition to being compelled to renounce elements of their history, culture and even their subjectivity. Without claiming to exhaust the theme, the paper brings, in the final considerations, some problematizations that reinforce the need for engagement in combating the manifestations of racism in contemporary society.

Keywords: quilombola communities; institutional racism; religious racism; Mato Grosso do Sul.
MANIFESTACIONES DEL RACISMO INSTITUCIONAL Y

\section{RELIGIOSO EN COMUNIDADES QUILOMBOLAS DE MATO GROSSO DO SUL} RESUMEN

Este artículo tiene como objetivo comprender las dimensiones institucional y religiosa del racismo que se manifiesta en las comunidades quilombolas en el Estado de Mato Grosso do Sul, en el Medio Oeste de Brasil. Como estrategia metodológica, se llevó a cabo una investigación cualitativa, en la que se utilizaron procesos de observación participativa, diálogos e interacciones con quilombolas de siete comunidades ubicadas en el Estado de Mato Grosso do Sul. En general, fue posible verificar que las manifestaciones de racismo institucional y religioso convierten a las comunidades quilombolas en espacios de gran precariedad, en que los quilombolas subsisten sin poder acceder a un conjunto de servicios públicos básicos, además de ser impulsados a renunciar a elementos de su historia, cultura y subjetividad. Sin pretender agotar el tema, el artículo trae, en las consideraciones finales, algunas problematizaciones que refuerzan la necesidad de involucrarse en la lucha contra las manifestaciones de racismo en la sociedad contemporánea.

Palabras clave: comunidades quilombolas; racismo institucional; racismo religioso; Mato Grosso do Sul/Brasil. 


\section{PROBLEMATIZAÇÕES INTRODUTÓRIAS}

O racismo representa um conjunto de práticas, historicamente determinadas, cujo propósito é estigmatizar, desumanizar e explorar permanentemente as pessoas negras, em função do seu pertencimento racial (Schucman 2014).

De uma maneira geral, o racismo perfaz um sistema de opressão que possui implicações de ordem política, cultural, social, econômica e psicológica (Zamora 2012), na medida em que impede que pessoas negras ocupem espaços de saber, de poder e de agência na estrutura social; estigmatiza aspectos do saber e da cultura negra (não raro, vista como desqualificada, inferior e profana); faz com que os negros estejam majoritariamente concentrados nos estratos socioeconômicos inferiores da sociedade; e coloca os sujeitos negros em um quadro de significativo e permanente sofrimento psíquico e emocional. Percebe-se que uma das consequências mais evidentes do racismo é a naturalização das desigualdades, em função da raça dos indivíduos.

Em uma reflexão sobre as implicações da política colonialista, implementada, sobretudo, pelos países europeus a partir do século XVI, o intelectual Aimé Césaire (1978) pondera que o racismo decorre da invenção da raça enquanto marcador para estigmatizar e explorar corpos, em uma relação de servidão dos povos colonizados para com os colonizadores europeus e brancos. Ainda segundo o autor, a lógica colonialista tomou os corpos brancos enquanto ideário de supremacia e altivez, ao passo em que os negros foram "construídos" como corpos passíveis de toda a sorte de disciplinamento, exploração e suplício.

A raça e, por conseguinte, o racismo perfazem construções sociais, inscritas em projetos hegemônicos de poder protagonizados por uma elite de pessoas majoritariamente brancas (Kilomba 2019). Desse modo, a pele negra representou o marcador para que, no seio do sistema capitalista, patriarcal e colonialista, um conjunto expressivo de pessoas fossem automaticamente consideradas como meras mercadorias, passíveis de toda a sorte de trocas, usos, abusos, violências, descarte e morte (Mbembe 2018).

Nesse sentido, a intelectual e ativista Angela Davis (2016) nos lembra que o racismo pode ser compreendido enquanto uma ideologia dominante ao longo dos últimos séculos, na qual os direitos, a humanidade e a altivez das pessoas negras foram permanentemente vilipendiados, sobretudo nos países ocidentais capitalistas, tendo como escopo a manutenção dos privilégios, dos lucros, do poder e do prazer de uma elite branca.

O racismo, enquanto um ardiloso mecanismo do projeto de poder eurocêntrico e branco, possui múltiplas dimensões (Moreira 2019). Muito embora a principal implicação das práticas racistas seja a estigmatização dos corpos negros, vale ressaltar que o racismo pode assumir uma dimensão institucional, que decorre do tratamento negligente e/ou excludente relegado às pessoas negras em alguma organização, seja ela pública, privada ou 
de interesse coletivo (Werneck 2016); pode também assumir uma dimensão religiosa, ligada, sobretudo, à estigmatização, à violência e à intolerância ante às manifestações religiosas afro-brasileiras, tais como a umbanda e o candomblé (Grosfoguel 2013).

Almeida (2019) salienta que as diversas dimensões do racismo (sejam de cunho institucional e/ou religioso) estão entranhadas em um contexto em que as práticas racistas apresentam-se enquanto algo estrutural nas mais diversas sociedades, sobretudo naquelas com passado escravocrata (tal como o Brasil). Ainda segundo o autor, o racismo estrutural perfaz um aspecto de viés ideológico, em que as (inter)relações entre pessoas se dão a partir de um quadro no qual uma elite majoritariamente branca empreende um conjunto de repertórios discursivos e práticos, que subjuga e explora um contingente significativo de pessoas cuja característica fundamental é o marcador da negritude.

Percebe-se que o racismo é um elemento estrutural nas sociedades contemporâneas quando, por exemplo, as pessoas que se autodeclaram negras, muito embora sejam a maioria absoluta da população brasileira, estão sub-representadas nos espaços de poder e na mídia, ao passo em que se encontram sobrerrepresentadas nas periferias, nas penitenciárias e nos obituários (Batista 2018; Nascimento 2019). Nesse sentido, uma sociedade é estruturalmente racista quando concede privilégios compulsórios e duradouros a uma elite de pessoas brancas, enquanto a maioria da sociedade, composta sobretudo por negros/as, padece vítima dos ardis das mais variadas práticas racistas (Almeida 2019).

Os territórios quilombolas, por reunirem um contingente de pessoas com uma mesma ancestralidade negra, representam alvos corriqueiros de práticas racistas das mais variadas dimensões (Souzas 2015). As comunidades quilombolas, contemporaneamente, representam espaços significativamente marginalizados, em que pessoas negras vivem, em sua grande maioria, de forma precária, com baixos níveis de renda, em locais degradados e/ou de difícil acesso, e com uma quase inexistente rede de provisão de serviços públicos (tais como água encanada, luz elétrica, escolas e afins) (Leite 2010; Gontijo et al. 2016).

Além do contexto de precariedade material, os quilombos brasileiros são espaços perpassados por variadas formas de violência - em 2017, só para citar um caso emblemático, o número de assassinatos em comunidades quilombolas no Brasil cresceu incríveis $350 \%$, em relação aos dados do ano imediatamente anterior (CONAQ 2018). Assim, nota-se que são urgentes e importantes os esforços no sentido de se(re) pensar o contexto de precariedade e as manifestações de racismo que recaem sobre as comunidades quilombolas, tendo como propósito a construção de caminhos que permitam aos grupos de pessoas negras subsistir a partir de uma acepção plena de humanidade e cidadania.

Existem investigações - tais como as de Arruda \& Gonçalves (2020), Fiabani (2008), além de Filho 
\& Germani (2014), só para citar alguns exemplos - que se debruçaram no esforço de caracterizar elementos do contexto de precariedade material das comunidades quilombolas no Brasil. Porém, quais as especificidades das dimensões do racismo que se manifestam contra comunidades quilombolas?

Desse modo, com base na problemática de pesquisa ora delineada, este artigo tem como objetivo compreender detalhes das dimensões institucional e religiosa do racismo que se manifestam em comunidades quilombolas no Mato Grosso do Sul, no Centro-Oeste brasileiro.

Em termos metodológicos, a pesquisa que subsidiou este artigo possui uma abordagem qualitativa e exploratória, uma vez que permitiu problematizar elementos da realidade de subalternidade, precariedade $\mathrm{e}$, consequentemente, de racismo (institucional e religioso) existente em territórios quilombolas no Mato Grosso do Sul, universo ainda pouco investigado nas pesquisas que se debruçaram sobre a realidade de comunidades quilombolas.

Além disso, vale destacar que os dados necessários para este artigo foram provenientes de processos de observação participante, interações e diálogos com os sujeitos residentes nos territórios quilombolas, de tal modo que objetivamos, a partir do contato permanente e regular com as comunidades, compreender elementos inerentes à realidade da vida nos territórios quilombolas pesquisados, tendo como perspectiva lentes teórico-epistemológicas provenientes dos estudos decoloniais.

Entendemos que o foco deste artigo em compreender as facetas institucional e religiosa do racismo no contexto de territórios quilombolas do Mato Grosso do Sul decorre da significativa invisibilidade e das constantes pressões sofridas por esses grupos. Nesse sentido, Urquiza \& Santos (2017) lembram que os contextos cultural e econômico sul-mato-grossenses, em que há uma prevalência da lógica econômica do agronegócio, contribuem para os processos de estigmatização, racismo, violência e expropriação dos quilombolas em relação aos territórios historicamente ocupados por esses grupos, sobretudo nas áreas rurais, em que a terra (especialmente quando muito fértil e agricultável) é um ativo importante para a (re) produção da lógica socioeconômica prevalente no Centro-Oeste brasileiro.

Portanto, com as reflexões e inferências que serão pormenorizadas neste artigo, pretendemos contribuir com a construção de uma agenda de pesquisas e reflexões que tenham como meta (re)conhecer a gravidade do quadro estrutural de racismo que recai sobre as pessoas negras e, particularmente, sobre os sujeitos quilombolas, em uma dinâmica que permita o engajamento na construção de possíveis sociabilidades, políticas públicas, epistemologias e conhecimentos antirracistas. 


\section{OS QUILOMBOS NO MATO GROSSO DO SUL: PRIMEIRAS APROXIMAÇÕES}

As interações com os territórios quilombolas sul-mato-grossenses ocorreram ao longo do ano de 2019, época em que um dos autores deste artigo realizou um estágio de pós-doutorado na Universidade Federal de Mato Grosso do Sul (UFMS), em que foi desenvolvido o projeto de pesquisa e extensão intitulado "Limites e possibilidades da difusão de iniciativas de turismo de base comunitária em territórios quilombolas: um estudo multicasos", chancelado pela universidade.

De uma maneira geral, o escopo do projeto em questão foi "pensar" os territórios quilombolas enquanto espaços com potencialidades para a difusão de experiências de turismo de base comunitária, muito embora o escopo do projeto, a princípio, tenha sido as reflexões em torno da atividade do turismo comunitário. Nas oportunidades nas quais interagimos com as comunidades quilombolas, foi possível presenciar uma série de outras questões que impactam a realidade quilombola, tais como a condição de precariedade em que vivem, além das múltiplas manifestações de racismo contra esses sujeitos.

Desse modo, tivemos a oportunidade de manter contatos regulares com sete comunidades quilombolas do Mato Grosso do Sul (Quadro 1).

Adotamos, enquanto pressuposto fundamental do esforço de pesquisa, a postura de pleno respeito

Quadro 1 - Comunidades quilombolas sul-mato-grossenses participantes no estudo.

\begin{tabular}{|l|l|l|}
\hline Nome do território & \multicolumn{1}{|c|}{ Cidade } & \multicolumn{1}{c|}{ Características gerais do território } \\
\hline $\begin{array}{l}\text { Comunidade } \\
\text { Quilombola } \\
\text { Chácara Buriti }\end{array}$ & $\begin{array}{l}\text { Campo Grande, capital do } \\
\text { Mato Grosso do Sul, Mato } \\
\text { Grosso do Sul }\end{array}$ & $\begin{array}{l}\text { Trata-se de uma comunidade localizada no perímetro rural, que desenvolve } \\
\text { atividades ligadas àricultura familiar, reconhecida como remanescente } \\
\text { de quilombo desde 2005. Possui aproximadamente 32 famílias }\end{array}$ \\
\hline $\begin{array}{l}\text { Comunidade } \\
\text { Quilombola Furnas } \\
\text { do Dionísio }\end{array}$ & $\begin{array}{l}\text { Jaraguari, cidade pouco } \\
\text { mais de 50 km distante de } \\
\text { Campo Grande }\end{array}$ & $\begin{array}{l}\text { Localiza-se no perímetro rural e empreende atividades ligadas à } \\
\text { agricultura familiar e ao turismo de aventura; conta com 100 famílias. } \\
\text { Reconhecida desde 2005 enquanto remanescente de quilombo }\end{array}$ \\
\hline $\begin{array}{l}\text { Comunidade } \\
\text { Quilombola de São } \\
\text { Benedito/Tia Eva }\end{array}$ & Campo Grande & $\begin{array}{l}\text { Localiza-se no perímetro urbano de Campo Grande, próximo à região central } \\
\text { da cidade, em um local em que residem aproximadamente 130 famílias. } \\
\text { Comunidade reconhecida como remanescente de quilombo desde 2008 }\end{array}$ \\
\hline $\begin{array}{l}\text { Comunidade } \\
\text { Quilombola de } \\
\text { Furnas dos Baianos }\end{array}$ & Aquidauana & $\begin{array}{l}\text { Localiza-se no perímetro rural e desenvolve atividades de agricultura } \\
\text { familiar e turismo no espaço rural; possui aproximadamente 20 } \\
\text { famílias. Reconhecida desde 2007 enquanto território quilombola }\end{array}$ \\
\hline $\begin{array}{l}\text { Comunidade } \\
\text { Quilombola } \\
\text { Campos Correa }\end{array}$ & $\begin{array}{l}\text { Corumbá, um relevante } \\
\text { destino turístico do Pantanal } \\
\text { de Mato Grosso do Sul }\end{array}$ & $\begin{array}{l}\text { Localiza-se no perímetro urbano e empreende atividades ligadas à } \\
\text { pesca; possui aproximadamente 20 famílias. Reconhecida desde 2013 } \\
\text { como remanescente de quilombo }\end{array}$ \\
\hline $\begin{array}{l}\text { Comunidade } \\
\text { Quilombola Família } \\
\text { Osório }\end{array}$ & Corumbá & $\begin{array}{l}\text { Localiza-se no perímetro urbano e empreende atividades ligadas à } \\
\text { pesca; possui 25 famílias. Reconhecida desde 2010 como remanescente } \\
\text { de quilombo }\end{array}$ \\
\hline $\begin{array}{l}\text { Comunidade } \\
\text { Quilombola Maria } \\
\text { Theodora }\end{array}$ & Corumbá & $\begin{array}{l}\text { Trata-se de uma comunidade de terreiro, ligada à umbanda, e localiza- } \\
\text { se no perímetro urbano de Corumbá; possui aproximadamente 22 } \\
\text { famílias. Reconhecida desde 2011 como remanescente de quilombo }\end{array}$ \\
\hline
\end{tabular}


e alteridade ante aos costumes, ritos e demais especificidades socioculturais manifestadas pelas comunidades. A nossa pretensão foi compreender as percepções decorrentes do lugar de fala das pessoas, ou seja: a nossa intenção foi refletir a partir do modo como as próprias pessoas que residem nos territórios quilombolas "leem" elementos do cotidiano e, mais especificamente, os indícios das eventuais práticas racistas que acometem as comunidades.

A filósofa Djamila Ribeiro (2019), ao discutir o conceito de lugar de fala, sugere que a produção de conhecimento, contemporaneamente, deve despirse de seu caráter eminentemente colonialista e, nesse sentido, captar a realidade a partir da perspectiva e do modo de vida manifestados pelos próprios sujeitos de pesquisa, não raro com base em epistemologias e formas próprias de produção de conhecimento.

Nas interações com as comunidades quilombolas participantes neste estudo, adotamos o expediente de, primeiramente, contatar as lideranças constituídas nos territórios - normalmente, as/ os presidentas/es das associações de moradores das comunidades -, numa dinâmica em que, a partir dos diálogos prévios, foi possível ganhar confiança e credibilidade por parte das comunidades, para que, desse modo, também fosse possível o diálogo com outros sujeitos dos territórios.
Vale salientar que os diálogos prévios com as lideranças constituídas nas comunidades foram cruciais no esforço de pesquisa, principalmente por compreendermos que, nesses espaços comunitários, identificar e respeitar as hierarquias sociais são expedientes fundamentais para o estabelecimento de vínculos e alianças, necessários para o esforço de pesquisa pretendido no âmbito deste estudo com as comunidades quilombolas sul-mato-grossenses.

Em campo, as nossas estratégias de pesquisa passaram pela observação atenta de detalhes da comunidade - tais como as condições físicas e estruturais das moradias, as formas de acesso às comunidades, a beleza cênica dos territórios, as atividades produtivas empreendidas, além dos espaços de sociabilidade e de culto. Ademais, nos diálogos empreendidos com os quilombolas, tentamos compreender, a partir da fala livre desses sujeitos, as características do cotidiano nesses territórios - sempre que as pessoas se mostravam dispostas ao diálogo, procurávamos estimular a fala desses sujeitos com questões genéricas, por exemplo: "conte como é o dia a dia aqui na comunidade" e "o que significa viver neste território?”.

Depois das nossas interações, in loco, nos territórios quilombolas, cada um dos integrantes da equipe de pesquisa fazia anotações em um diário de campo (sempre preenchido a posteriori). Em síntese, as anotações tinham como propósito 
a sistematização das principais observações e inferências decorrentes das interações em campo, além do registro das próprias percepções dos quilombolas, tendo como base a compreensão dos elementos que afetam esses sujeitos. Regularmente, a equipe de pesquisa fez reuniões presenciais, tendo como escopo a troca de experiências e a "socialização" das principais inferências feitas pelos pesquisadores.

$\mathrm{Na}$ medida em que fomos desenvolvendo vínculos com os quilombolas, em função das nossas muitas idas e vindas nas comunidades, fomos autorizados a registrar, por intermédio de fotografias, alguns detalhes e características da realidade nos territórios. Só fizemos as fotografias na medida em que os próprios sujeitos, declaradamente, nos autorizavam.

Foi curioso perceber que o registro fotográfico, na maioria das circunstâncias, foi visto por parte das comunidades como algo positivo. Pareceunos que, à ótica dos quilombolas, o fato de haver anseio pelo registro de características do território decorreu de um interesse genuíno na constituição sociocultural e paisagística da comunidade, (re)significando o contexto de isolamento e precariedade no qual os quilombolas vivem.

Todos os territórios que visitamos são certificados pela Fundação Cultural Palmares ${ }^{1}$. De todo modo, muito embora sejam oficialmente reconhecidas, nenhuma das comunidades teve seu território efetivamente titulado, uma vez que os processos de demarcação e titulação das terras ainda se arrastam nas autarquias públicas responsáveis por essas fases do processo.

Logo nas primeiras interações que estabelecemos com os quilombolas sul-matogrossenses, percebemos que a constituição das comunidades é marcada por significativa heterogeneidade, ou seja: residem nos territórios quilombolas, além dos descendentes diretos dos fundadores das comunidades, um conjunto de agregados/as, a exemplo de cônjuges e parentes próximos (de segundo e terceiro graus) que, paulatinamente, foram sendo incorporados ao contexto comunitário e ao cotidiano dos quilombos.

A constatação é coerente com as reflexões propostas por Schmitt et al. (2002), que reiteram que os quilombos, contemporaneamente, representam espaços significativamente heterogêneos, em que um conjunto diverso de pessoas com uma mesma ancestralidade negra criam laços de comunhão e sociabilidade para, juntas, combaterem as múltiplas formas de opressão das sociedades capitalistas modernas. Isso contrasta com a

1 Autarquia atualmente vinculada à Secretaria Especial da Cultura do Governo Federal, que possui a obrigação de identificar, reconhecer, delimitar, demarcar e titular os territórios quilombolas, conforme disposições do Decreto n. 4.887, de 20 de novembro de 2003 (Brasil 2003). 
percepção "naturalizada" pelo senso comum, que normalmente liga os quilombos à ideia de espaços exclusivamente ocupados por descendentes diretos de negros escravizados, sobretudo à época do Brasil colonial (Fiabani 2008).

Nos diálogos com os quilombolas sul-matogrossenses, ao tentarmos compreender elementos da história das comunidades, constatamos que são muito recentes os esforços de se levantar e sistematizar os detalhes da origem das comunidades e dos seus respectivos fundadores. Foi possível perceber que só a partir de 2003, com a edição do Decreto n 4.887 (Brasil 2003), que permitiu o reconhecimento e a titulação dos territórios quilombolas, muitas das comunidades sul-mato-grossenses passaram a se organizar e a se "enxergar" enquanto quilombos, representando os primeiros esforços de resgate de sua história e identidade.

Em uma sociedade tal como a brasileira, na qual as pessoas negras foram historicamente subalternizadas e invisibilizadas, sabemos que foram inúmeras as tentativas de impelir os indivíduos negros a renunciarem elementos de sua história (Nascimento 2019). De todo modo, na medida em que o aparato jurídico-normativo permitiu que territórios de histórica resistência e luta, tais como os quilombos, fossem (re)conhecidos, demarcados, titulados e preservados, percebemos que tal expediente estimulou, nos próprios quilombolas, um desejo de resgatar a história e os motivos pelos quais os territórios que ocupam são importantes e carregados de múltiplos significados.

Além disso, vale ressaltar que os estudos antropológicos e historiográficos necessários para o reconhecimento, a demarcação e a titulação dos quilombos representaram "provocações" para que os quilombolas, de forma coletiva e dialogada, resgatassem os aspectos de sua ancestralidade e da própria constituição das comunidades.

Mesmo que de modo ainda esparso, foi possível depreender que os fundadores das comunidades quilombolas sul-mato-grossenses foram originários dos estados de Minas Gerais, Goiás e até da Bahia, que se dirigiram ao sul do então estado de Mato Grosso, já em fins do século XIX, com o propósito de ocupar porções de terras, não raro como meeiros, posseiros ou mesmo titulares de pequenas parcelas de terra, tendo como escopo o desenvolvimento de atividades ligadas à agricultura de subsistência.

Urquiza \& Santos (2017), que empreenderam uma pesquisa de caráter documental e historiográfico sobre os quilombos do Mato Grosso do Sul, corroboram essas observações e acrescentam que os fundadores dos quilombos sul-mato-grossenses eram, em sua grande maioria, pessoas negras já libertas que, em busca de melhores condições de vida, rumaram para o 
Centro-Oeste brasileiro, na esperança de subsistir com um pouco mais de dignidade.

Um aspecto que, em muitas circunstâncias, a historiografia convencional negligencia é a importância das comunidades negras na constituição social, cultural e econômica do Centro-Oeste brasileiro. Ao lermos Oliveira (2013), percebemos que os esforços de traçar as bases históricas, socioculturais e econômicas do Centro-Oeste brasileiro, no geral, dão especial ênfase à influência dos povos provenientes do Sul do Brasil (em sua maioria, descendentes de europeus brancos), além dos imigrantes paraguaios, bolivianos e até japoneses, de tal modo que permanecem invisibilizados os elementos da cultura e da própria influência que os povos negros e indígenas legaram à porção Centro-Oeste do Brasil.

Ao interagirmos com os quilombolas do Mato Grosso do Sul, foi possível constatar que o costume da produção e do consumo de rapadura - que perfaz um doce feito a partir da cana-de-açúcar, não raro consumido junto com café, nos fins de tarde, normalmente sob a sombra de alguma árvore frondosa - e o hábito de se frequentar determinadas festas populares ${ }^{2}$ representam alguns exemplos de elementos entranhados na cultura sulmato-grossense e que nutrem uma relação direta com os processos de surgimento e constituição de comunidades quilombolas no Mato Grosso do Sul.

Em suma, os costumes e hábitos descritos nos foram relatados enquanto aspectos, culturalmente determinados, que se originaram a partir dos fundadores das comunidades e que foram legados aos descendentes, de geração em geração. Muito embora tais costumes e hábitos tenham sido negligenciados e invisibilizados durante muito tempo, percebe-se que, contemporaneamente, com o (re)conhecimento das comunidades enquanto um grupo quilombola, tais histórias foram resgatadas e (re)contadas, implicando orgulho e senso de pertencimento por parte dos sujeitos com os quais interagimos.

Além disso, nos chamou a atenção a recorrência das menções aos elementos da negritude, tais como a cor da pele e a constituição do cabelo, enquanto aspectos que caracterizam as pessoas das comunidades e que, desse modo, conferem identidade aos sujeitos que residem nos territórios quilombolas do Mato Grosso do Sul.É muito potente pensarmos na(re)valorização dos traços da negritude e da própria trajetória das comunidades, uma vez que tais elementos, que geram identidade e pertencimento, implicam maior desejo de permanecer no território e defendê-lo contra tentativas que objetivam tornar inviável a vida nos quilombos.

Também foi possível perceber que os quilombos

2 São exemplos disso os festejos de São Benedito, que ocorrem sempre em maio, na comunidade quilombola de São Benedito/Tia Eva, no município de Campo Grande, e o Festival da Rapadura, que acontece na comunidade de Furnas do Dionísio, no município de Jaraguari. 
sul-mato-grossenses são perpassados por uma realidade de isolamento e precariedade material. São significativamente ruins as condições das vias de acesso às comunidades. No caso dos quilombos que se localizam em área rural, as estradas são esburacadas e sem pavimentação, o que torna difícil o deslocamento, em especial na época de chuvas, período em que as estradas se transformam em verdadeiros atoleiros. Mesmo no caso das comunidades que estão em áreas urbanas, o acesso é complicado, visto que não há placas e/ou sinalizações que identifiquem as comunidades, o que corrobora a realidade de isolamento e invisibilidade dos territórios quilombolas sul-mato-grossenses. No caso, em específico, das comunidades de Campos Correa e Família Osório, que se localizam no perímetro urbano de Corumbá, o acesso aos territórios se dá por ruas estreitas, muito esburacadas e sem qualquer tipo de infraestrutura.

As moradias nas comunidades quilombolas são simples e, em alguns casos, precárias - há residências em certos territórios, como em Furnas do Dionísio ou em Família Osório, que são cobertas de modo improvisado, o que faz com que os moradores fiquem vulneráveis no período de chuvas e ventos fortes. Percebemos, ainda, que várias residências são feitas com materiais reaproveitados, além de carecerem de alguns itens básicos, como revestimento nas paredes, no chão e portas e janelas adequadamente instaladas - só para citar alguns exemplos.
Por fim, ressalte-se que muitas comunidades carecem de infraestrutura básica (água encanada e luz elétrica, por exemplo), o que faz com que os quilombolas sejam colocados à margem de uma concepção plena de cidadania.

Desse modo, entendemos que a conjuntura de isolamento e precariedade da vida nas comunidades quilombolas decorre, em grande medida, do racismo que recai sobre os quilombolas, conforme discutiremos na sequência deste texto.

O Quadro 2 sumariza os principais indícios de racismo institucional e religioso que foram constatados ao longo das interações com as

Quadro 2 - Sumarização dos indicativos de racismo institucional e religioso nos quilombos

\begin{tabular}{|c|c|}
\hline $\begin{array}{l}\text { Dimensões do } \\
\text { racismo }\end{array}$ & $\begin{array}{c}\text { Indicativos evidenciados } \\
\text { nos territórios }\end{array}$ \\
\hline Institucional & $\begin{array}{l}\text { Morosidade no processo de } \\
\text { regularização fundiária dos } \\
\text { territórios quilombolas por } \\
\text { parte do governo federal } \\
\text { Recusa em oferecer } \\
\text { um padrão adequado } \\
\text { de serviços públicos } \\
\text { às comunidades (água } \\
\text { encanada, luz elétrica, além } \\
\text { de saúde, educação e lazer) } \\
\text { Ineficiência do poder } \\
\text { judiciário na recepção de } \\
\text { demandas dos quilombolas } \\
\text { por direitos básicos }\end{array}$ \\
\hline Religioso & $\begin{array}{l}\text { Tentativa de evangelização } \\
\text { dos quilombolas, sobretudo } \\
\text { por parte de denominações } \\
\text { religiosas cristãs e } \\
\text { eurocêntricas } \\
\text { Intolerância quanto aos } \\
\text { rituais ligados às religiões } \\
\text { de matriz afro-brasileira, } \\
\text { inclusive nas comunidades } \\
\text { de terreiro }\end{array}$ \\
\hline
\end{tabular}


comunidades quilombolas sul-mato-grossenses.

Entendemos que as dimensões institucional e religiosa do racismo não se manifestam de forma isolada: representam eventos marcadamente interseccionados que, ao acometerem os quilombolas, implicam significativo sofrimento e precariedade na vida desses sujeitos. Porém, para fins didáticos, optamos por apresentar em separado as especificidades de cada uma dessas formas de racismo. Ao final do artigo, oferecemos um panorama dos múltiplos racismos contra as comunidades quilombolas, revelando o caráter interseccional deste fenômeno e discutindo caminhos a partir dos quais poderemos somar esforços às práticas e epistemes antirracistas.

\section{3. "E NÃO SOMOS CIDADÃOS?": EM TELA, 0 RACISMO INSTITUCIONAL}

O racismo institucional perfaz o conjunto de práticas, perpetradas por organizações (sejam elas públicas ou privadas), que subjugam, inferiorizam e até agridem pessoas de determinados perfis raciais, impedindo e/ou tornando precário o acesso de certos sujeitos aos bens e serviços que idealmente deveriam ser oferecidos pela organização (Werneck 2016). A circunstância em que, por exemplo, uma pessoa negra não consegue acessar, adequadamente, os bens e serviços de determinada empresa e/ou autarquia pública pelo puro e simples fato de ser negro/a perfaz uma situação de racismo institucional.

Hesse (2004) sugere que o racismo institucional pode ser identificado por intermédio de atitudes, processos organizacionais e/ou comportamentos manifestados por gestores e/ou colaboradores de uma organização, que fazem com que pessoas sejam estigmatizadas e inferiorizadas em função de sua raça e de sua cor. Fonseca (2015), por seu turno, lembra que o racismo institucional pode manifestar-se independentemente do caráter intencional da organização, ou seja: a omissão e/ou negligência da organização em criar mecanismos que efetivamente combatam qualquer tipo de tratamento diferenciado às pessoas de determinado pertencimento racial também são evidências de racismo institucional.

As práticas de racismo institucional são especialmente paradigmáticas e graves quando ocorrem no âmbito de uma autarquia pública que, em tese, deveria servir a toda a sociedade, sem distinções e/ou tratamentos diferenciados de quaisquer ordens. Na medida em que as organizações públicas empreendem, mesmo que de modo não intencional, práticas de racismo institucional, percebe-se que há, nessas organizações, múltiplas concepções de cidadania, na qual determinados sujeitos - normalmente brancos e ricos - acessam plenamente os bens e serviços que essa autarquia 
se dispõe a oferecer, ao passo em que as pessoas negras, pobres e periféricas são colocadas à margem, como se compusessem uma espécie de subcidadãos, conforme sugere Mbembe (2018).

Logo nas nossas primeiras interações com os grupos quilombolas, foi possível perceber um padrão de negligência por parte de determinadas autarquias públicas no atendimento a direitos básicos que competem às comunidades quilombolas.

Há uma significativa morosidade, por parte do poder público, no processo de demarcação e titulação dos territórios ocupados pelas comunidades. O Instituto Nacional de Colonização e Reforma Agrária (INCRA), autarquia que possui o protagonismo na demarcação dos territórios, esteve poucas vezes nos quilombos, de forma que as próprias comunidades não sabem, em detalhes, o status do processo de regulação fundiária de seus territórios, ou o horizonte de tempo necessário para que tenham a efetiva titulação das terras que seus antepassados lhes deixaram.

Vale lembrar que alguns quilombos nos quais estivemos - como as comunidades de Chácara Buriti e Furnas do Dionísio - foram legalmente reconhecidos como comunidades quilombolas em 2005, de tal modo que o processo para a efetiva delimitação e titulação da área que é de direito da comunidade se arrasta desde então, sem que o INCRA, ou mesmo outras autarquias competentes, seja capaz de comunicar, a bom termo, de modo democrático e transparente, as dinâmicas e os detalhes de todo esse processo. Ademais, é importante frisar que as comunidades não se revelaram participantes ativas do processo legal de demarcação e titulação de seus territórios - o que, no nosso entender, contraria o disposto no art. $6^{\circ}$ do próprio Decreto n. 4.887/2003, que assegura aos quilombolas "[...] a participação em todas as fases do procedimento administrativo [de regulação fundiária dos territórios], diretamente ou por meio de representantes por eles indicados" (Brasil 2003). Em diálogos com servidores do INCRA, no Mato Grosso do Sul, foi possível apurar que tal autarquia, ao longo dos últimos anos, foi acometida por um processo de escassez de recursos financeiros e humanos. Das comunidades contempladas neste estudo, os territórios de Furnas do Dionísio, São Benedito/Tia Eva e Chácara Buriti estão em um estágio bem avançado no processo de titulação das terras que pertencem à comunidade, porém tal expediente não chega a termo em função da ausência de motivação política e institucional por parte do governo federal, segundo relatos dos servidores do INCRA. Tal morosidade é, por si só, indicativa de práticas de racismo institucional contra as comunidades, dentro de uma dinâmica em que os grupos quilombolas se veem numa condição de subcidadania, na medida em que têm um conjunto de direitos que não são, stricto sensu, respeitados em sua plenitude. 
O racismo institucional que decorre da atuação do INCRA, em muitas circunstâncias, advém de toda uma agenda política e econômica cujo propósito é relegar os negros e, particularmente, os quilombolas à condição de permanente subalternidade. Para ilustrarmos um exemplo de tal aspecto, o relatório da CONAQ (2018) aponta que o orçamento do INCRA para a condução de processos de regularização fundiária de quilombos em todo o território nacional caiu $86 \%$ em 2017, comparando-se com o valor do orçamento em 2010 - em termos monetários, houve uma queda dos R \$ 25,8 milhões registrados em 2010 para pouco mais de R\$ 3,5 milhões de verba autorizada em 2017.

A falta da titulação dos territórios faz com que as comunidades sejam acometidas por outros eventos - no nosso entender, também caracterizados como manifestações de racismo institucional - que tornam a vida nos quilombos ainda mais complicada.

Nas nossas visitas às comunidades, constatamos que é muito precário o acesso à água encanada e à luz elétrica, inclusive nos quilombos que se localizam no perímetro urbano dos municípios, de tal modo que os moradores, para disporem de água e luz em suas residências, normalmente recorrem aos "gatos", ligações clandestinas que, ao serem feitas, oferecem perigo às comunidades. Ao indagarmos o motivo pelo qual o quilombo não consegue acessar água encanada e luz elétrica, foi-nos apresentado o relato de que as próprias companhias de distribuição de água e luz do estado e dos municípios se recusam a oferecer esses itens aos quilombolas, sob o argumento de que não é possível instalar medidores de água e luz em localidades nas quais os moradores não possuem a efetiva titulação das áreas em que habitam. Porém, como dispor do título de posse da terra (e acessar "legalmente" a água e a luz) se tal documento carece da finalização do processo de regularização fundiária dos quilombos, sob a batuta do INCRA?

Foi recorrente, nos discursos dos sujeitos quilombolas, a demanda por acesso à água e à luz provenientes das companhias oficiais, uma vez que o acesso adequado implica um sentimento de cidadania, à ótica dos quilombolas.

Uma realidade particular que nos chamou a atenção, e que merece ser aqui pormenorizada, foi a da comunidade de Campos Correa, que se localiza a pouco menos de dois quilômetros de distância da região central do município de Corumbá, no extremo oeste de Mato Grosso do Sul. Muito embora a comunidade esteja no perímetro urbano de Corumbá, cercada de áreas eminentemente urbanizadas e povoadas, ainda assim o território em análise não dispõe de energia eletrificada e nem de água encanada, em função da ausência da definitiva regularização fundiária 
da área historicamente ocupada pela comunidade.

Na Figura 1, é possível ver, logo no centro do registro fotográfico, um emaranhado de fios que interligam as casas da comunidade de Campos Correa: trata-se de fios que levam eletricidade às residências de modo precário e arriscado, uma vez que, segundo os próprios moradores, há o risco permanente de que algum tipo de incêndio ocorra na comunidade, em função do caráter improvisado dos "gatos" da energia elétrica. Além disso, vale dizer que, ao circularmos pela comunidade, foi possível perceber algumas tubulações expostas, não raro com remendos de borracha feitos de forma improvisada e precária, para que as residências possam acessar água de forma um pouco mais prática.

Foi paradigmático notar que, contígua à comunidade, há uma residência "lida" pelos quilombolas como de alto padrão (Figura 1), muito provavelmente suprida com água encanada e luz elétrica disponibilizadas pelas concessionárias de serviços públicos que atuam no município de Corumbá. Tal residência localiza-se em um terreno grande, possui paredes revestidas, ornamentadas e pintadas, de tal modo que nos fundos há uma espécie de deck que permite aos moradores o vislumbre, por cima do muro, de toda a paisagem da planície pantaneira, que fica contígua à residência e também à área ocupada pela comunidade quilombola.
Os relatos dos quilombolas de Campos

Correa dão conta de que essa casa foi construída, de modo não consentido e ilegal, em uma área que historicamente pertenceu à comunidade, dificultando sensivelmente o acesso ao território quilombola. Na Figura 1, é possível observar um pequeno corredor (chamado pelos moradores de “trieiro”) que representa o único acesso à área atualmente ocupada pela comunidade.

Vale destacar, ainda, que a altura e a presença de arames eletrificados no topo do muro sugerem uma tentativa de isolamento em relação à comunidade quilombola, expediente que pode ser "lido" enquanto fonte de racismo por parte dos residentes. Segundo relatos dos quilombolas, os moradores da referida casa não se mostram acessíveis para diálogos, o que faz com que os próprios quilombolas interpretem esse tipo de atitude como racismo, tal como se as pessoas que residem na comunidade fossem fonte de algum tipo de ameaça ou perigo iminente.

Essa realidade da comunidade de Campos Correa é uma constante nas demais comunidades quilombolas pesquisadas. Para acessar, por exemplo, as comunidades de Furnas do Dionísio e Furnas dos Baianos, que se localizam em áreas rurais, é necessário trafegar por longos percursos de estradas de terra, que ficam precárias e intransitáveis na época de chuvas, sem que o 

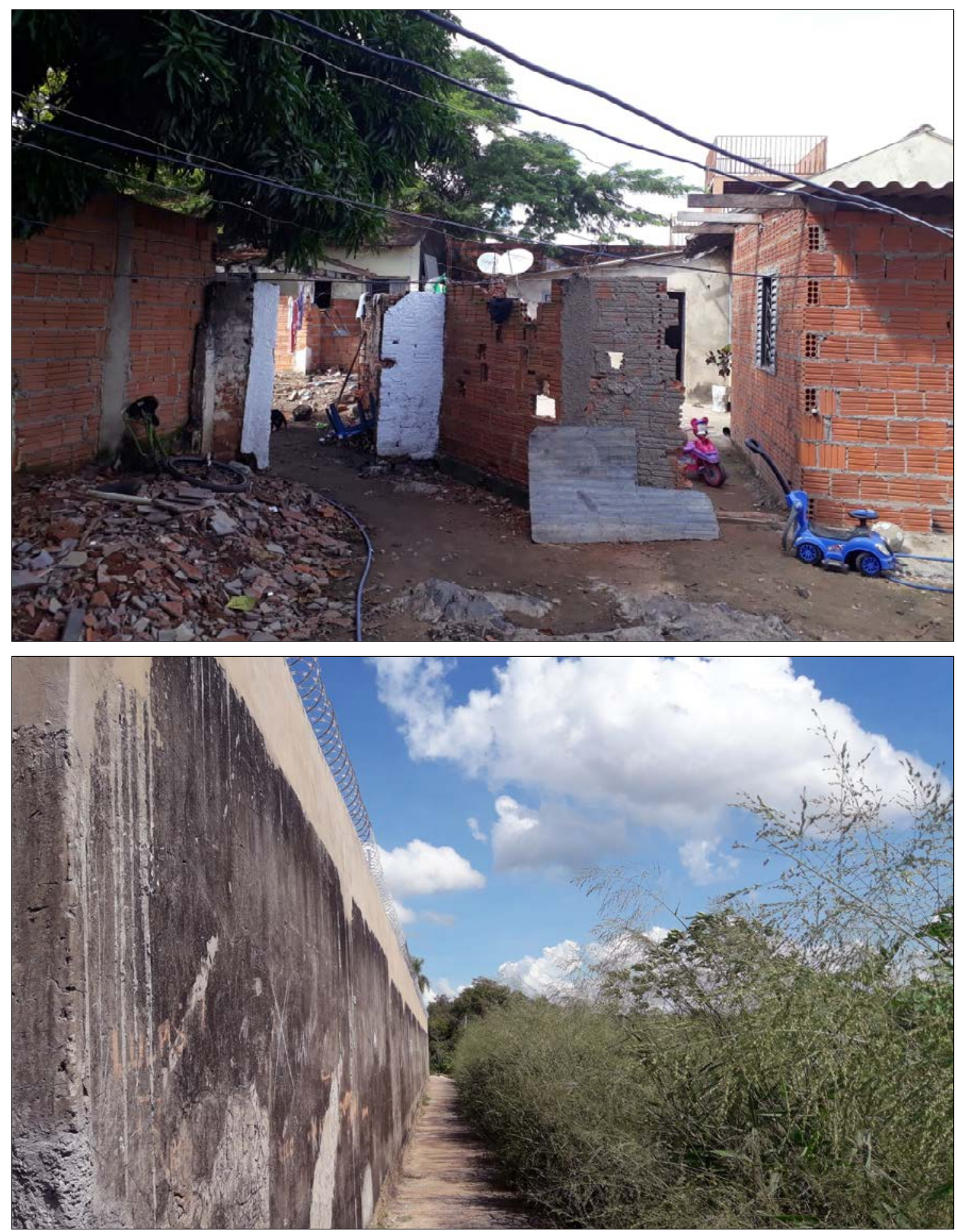

Figura 1 - Detalhes da realidade na comunidade quilombola de Campos Correa. Fotos: Dyego de Oliveira Arruda (2020). 
conjunto de políticas públicas seja efetivo em permitir a adequada conservação das estradas e, por conseguinte, o tranquilo e regular acesso dos moradores às comunidades.

Vale mencionar, ainda, a carência do adequado oferecimento de serviços públicos de educação, saúde e lazer nas comunidades quilombolas. Mesmo nos territórios nos quais há escolas públicas destinadas à comunidade - tais como em Furnas do Dionísio -, existe o permanente risco de fechamento destes estabelecimentos de ensino, sob o argumento, reiteradamente manifestado pelos agentes do poder público local, de que o cenário contemporâneo de crise fiscal e contingenciamento de recursos públicos requer esse tipo de alternativa. Ademais, deve-se registrar que não há opções, nas comunidades, de cursos de qualificação profissional aos moradores, muito embora tal expediente seja uma demanda recorrente. Por fim, o transporte escolar, normalmente oferecido pelas prefeituras, é significativamente irregular no caso das comunidades que estão em área rural, além de as condições de conservação dos veículos escolares serem precárias, fazendo com que as crianças e os adolescentes das comunidades fiquem sem frequentar as aulas quando os veículos estragam (o que é algo corriqueiro, segundo os quilombolas).
Quanto aos serviços de saúde, percebemos que não há uma agenda sistemática de atendimento às populações quilombolas com as quais interagimos. Recentemente, mesmo a Estratégia de Saúde da Família (ESF), que perfaz uma agenda de saúde pública implementada na década de 1990 pelo Ministério da Saúde, não atende regularmente as comunidades, sobretudo em função da escassez de profissionais que desempenham esse tipo de trabalho. Em Chácara Buriti, comunidade quilombola localizada no perímetro rural do município de Campo Grande, por exemplo, a despeito de haver um conjunto significativo de pessoas que sofrem de problemas crônicos (tais como hipertensão e diabetes, que acometem a população negra de modo recorrente), não há uma estratégia regular e coordenada de atendimento a essas pessoas, as quais não raro têm dificuldades até para acessar determinados remédios de consumo mais corriqueiro.

Em relação às opções de lazer, as comunidades não dispõem de alternativas de entretenimento, tais como praças e/ou parques destinados aos moradores. Nos quilombos em que há escolas públicas - tais como em Furnas do Dionísio e em São Benedito/Tia Eva -, a única opção de lazer da comunidade é a quadra da escola. Vale registrar que os próprios quilombolas 
entendem como um problema a falta de opções de lazer nas comunidades, sobretudo para as crianças, que, no geral, acabam se envolvendo em atividades arriscadas e/ou não desejáveis como forma de entretenimento.

É importante ressaltar que, em uma demonstração de organização e ciência quanto aos direitos básicos que lhes competem, os quilombolas dirigiram-se ao Ministério Público Federal (MPF) e protocolaram uma série de denúncias, dando conta do quadro de negligência no oferecimento de serviços públicos às comunidades - porém, até o fim de 2019 não havia qualquer decisão e/ou diligência proferida pelo MPF, em atenção às demandas manifestadas pelas comunidades. Os primeiros processos datam de 2012, sem que, desde então, qualquer tipo de decisão, mesmo que provisória e/ou em caráter emergencial, tenha sido definitivamente tomada.

O padrão de negligência - sobretudo por parte das autarquias públicas e concessionárias de serviços públicos, mas também do MPF, que deveria zelar pela observância aos direitos básicos das populações quilombolas - representa indícios de racismo institucional contra os quilombolas, uma vez que tais sujeitos são compulsoriamente impelidos a uma condição de subcidadania.

\section{4. "QUEM É DE AXÉ, NÃO DIZ QUE É": EM TELA, 0 RACISMO RELIGIOSO}

O racismo religioso representa o conjunto de práticas que tem como propósito estigmatizar e impelir múltiplas formas de violência, inclusive física, às pessoas que professam religiões e crenças que escapam à cosmovisão eurocêntrica e branca (Grosfoguel 2013).

Leandro \& Sanfilippo (2018) lembram que o racismo religioso está na própria constituição histórica e sociocultural do Brasil, uma vez que os colonizadores europeus e brancos, assim que aportaram em terras brasileiras, logo trataram de "catequisar" os indígenas que habitavam o país, tendo como escopo fazer com que esses sujeitos renunciassem às suas crenças e hábitos de culto, a fim de que professassem uma fé cristã eurocentrada. O mesmo expediente de catequização compulsória ocorreu, de forma violenta, com os africanos escravizados que também aportaram em terras brasileiras a partir de meados do século XVI.

Contemporaneamente, o racismo contra as religiões de matriz afro-brasileira (a umbanda e o candomblé, por exemplo) ocorre por intermédio da naturalização do medo e da violência contra as pessoas que professam tais religiões; pela profanação e destruição dos locais de culto (terreiros); pelo desrespeito e até proibição para que certos rituais ocorram em determinados 
espaços; sem contar a invisibilidade, no tecido social contemporâneo, de aspectos da cosmovisão ligada às religiões afro-brasileiras, que poderiam constituir elementos para a (re)produção de conhecimentos e de pedagogias socialmente relevantes (Russo \& Almeida 2016).

O babalorixá (chefe espiritual de religiões de matriz afro-brasileira) e doutor em ciências sociais Rodney William (2019) nos lembra que o racismo religioso também é evidenciado na medida em que certos elementos que são simbólicos nos rituais característicos das religiões de matriz afrobrasileira (tais como os turbantes e os colaresguia) são usados de forma descontextualizada por pessoas que não são ligadas às religiões em questão. Ademais, o mesmo autor destaca, ainda, que o racismo religioso que impera na sociedade brasileira faz com que as pessoas ligadas às religiões afro-brasileiras não tenham plena liberdade de professar a sua fé publicamente, numa dinâmica em que tais sujeitos permanecem nas sombras, invisibilizados ante o universo de intolerância e violência para com essas religiões.

Fonseca \& Giacomini (2013) salientam que o racismo religioso leva um contingente significativo de pessoas que professam uma fé ligada às religiões de matriz afro-brasileira de modo reservado e até escondido a, em ambientes públicos (no local de trabalho ou mesmo no bairro em que moram), se dizerem pertencentes às religiões cristãs, sobretudo ao protestantismo neopentecostal e ao catolicismo.

Foi possível perceber, nos territórios quilombolas sul-mato-grossenses, que a temática da religiosidade é delicada e intrigante. Dos sete quilombos que fizeram parte da pesquisa, em apenas um há uma aderência declarada e pública da comunidade à religião de matriz afro-brasileira - trata-se do território quilombola de Maria Theodora, no qual há um terreiro de umbanda. Nas outras seis comunidades, foi possível constatar presença maciça das religiões católica e protestante neopentecostal, que dispõem de templos nos quais há regularidade na realização de cultos e/ou missas, em uma dinâmica em que as religiões de matriz afro-brasileira são vistas como tabu e até como algo socialmente estigmatizado e proibido no âmbito dessas comunidades.

Chama a atenção, em vários territórios nos quais estivemos, a imponência dos templos ligados às religiões cristãs, que contrasta com a simplicidade e até com a precariedade do cotidiano nas comunidades. No território quilombola Chácara Buriti, por exemplo, logo ao adentrarmos nele, é possível notar a presença de um grande templo de uma denominação religiosa neopentecostal, localizado em uma área privilegiada da comunidade, construído em alvenaria e com pintura irretocável, além de 
possuir um ornamentado jardim, aspectos estes que contrastam com a realidade das casas e das demais construções da comunidade. A imponência do templo religioso de Chácara Buriti marca, de forma evidente, a presença dessa religião na comunidade, processo que implica potenciais contradições com a história e a cosmovisão professada por certa parcela de residentes no território quilombola.

A imponência do templo em análise marca um possível desejo, sobretudo por parte de grupos e indivíduos que não estão diretamente envolvidos com a trajetória da comunidade, de catequizar os sujeitos quilombolas.

De um modo geral, os quilombolas nos relataram que a significativa maioria dos moradores, atualmente, pertencem a uma denominação religiosa neopentecostal e frequentam regularmente os cultos no templo existente na comunidade. Ao tangenciar a temática das religiões afro-brasileiras, no entanto, notamos um significativo desconforto por parte das pessoas, o que, para nós, foi um indicativo de que este assunto é um tabu para os moradores, que, no nosso entender, foi incutido pelo conjunto de valores e princípios caros para as religiões cristãs e eurocêntricas.

Ainda em Chácara Buriti, em um diálogo mais reservado com uma moradora, nos foi relatado que a chegada maciça das religiões cristãs (católica e evangélica neopentecostal) no território provocou uma espécie de apagamento de algumas tradições da comunidade. Segundo esta pessoa, o conjunto de princípios morais e éticos incutidos na comunidade pelos líderes religiosos cristãos fez com que, por exemplo, a atividade dos benzedores e benzedeiras fosse estigmatizada a ponto de quase desaparecer da comunidade. Ademais, segundo o mesmo relato, aqueles/as que professam uma fé ligada às religiões de matriz afro-brasileira são tacitamente proibidos de realizar, no território, atividades eminentemente ligadas a esse tipo de religiosidade, o que faz com que esses sujeitos só consigam manifestar este aspecto de sua subjetividade em outros espaços, longe do território quilombola.

Esses fenômenos também foram evidenciados em outros territórios nos quais estivemos. Em Furnas do Dionísio, segundo os relatos de alguns moradores, a chegada maciça das religiões protestantes neopentecostais fez com que a comunidade fosse paulatinamente perdendo a relação com a capoeira, com a Catira e com o Engenho Novo - as duas últimas, danças populares e folclóricas, que eram apresentadas na época da produção da rapadura (um item também cultural e historicamente determinado na comunidade), além de antes serem também 
performadas em outras festividades de cunho religioso e cultural que ocorriam no território.

Já em São Benedito/Tia Eva, quando procuramos compreender a temática da religiosidade no âmbito do território, nos deparamos com uma outra realidade: a matriarca e fundadora da comunidade (a tia Eva Maria de Jesus, que fora escravizada quando ainda jovem na região de Goiás, tendo chegado já liberta, por volta de 1905, na região de Campo Grande) era católica e devota de São Benedito. Em função da influência de tia Eva, uma considerável parcela da comunidade professa a fé católica e frequenta uma pequena capela, construída na região em devoção a São Benedito, como homenagem a ele. Entretanto, percebemos que a capela da comunidade se encontra em precário estado de conservação e que não há missas regulares nesse local, pelo simples fato de a arquidiocese de Campo Grande não a reconhecer³.

Além disso, um relato acerca das manifestações de fé ligadas às religiões afro-brasileiras informa que, na comunidade, "quem é de axé, não diz que é", o que faz com que seus praticantes permaneçam às sombras, conforme no lembra o babalorixá e doutor Rodney William (2019).

Portanto, os aspectos brevemente sumarizados nos parágrafos anteriores nos levam a concluir que as manifestações de racismo religioso ocorrem nos territórios quilombolas quando: (a) a presença e a adesão a determinadas religiões cristãs e eurocêntricas implicam um processo de apagamento da história, dos ritos e costumes que, eventualmente, compõem pilares importantes da cultura nas comunidades quilombolas; e (b) as manifestações de crenças e costumes ligados às religiões afro-brasileiras são vistas de forma estigmatizada, o que faz com que seus adeptos não consigam explicitar estes aspectos de forma pública, sem receios e sem os riscos de eventuais reprimendas e violências.

Vale ressaltar que não pretendemos, neste texto, propor uma interpretação essencialista acerca das comunidades e de seus moradores, tal como se eles devessem professar uma religião específica. O racismo religioso, em nossa visão, evidencia-se quando as comunidades quilombolas são tomadas como espaços passíveis de esforços de catequização, de tal modo que uma eventual adesão por uma determinada religião implica o apagamento de elementos da história e da cultura das comunidades, ou mesmo a proibição de se professar uma outra religião, tal como aquelas ligadas à umbanda

3 Na página oficial da arquidiocese de Campo Grande, não há qualquer menção à capela da comunidade de São Benedito/Tia Eva enquanto um espaço de culto que compõe a estrutura local da igreja católica. 
e ao candomblé, por exemplo.

Dadas as reflexões feitas até aqui, uma pergunta que ainda permanece é: afinal, qual a realidade, à ótica da temática do racismo religioso, da comunidade quilombola de Maria Theodora, em Corumbá, na qual há um terreiro de umbanda?

Logo nas nossas primeiras interações com a comunidade Maria Theodora, fomos surpreendidos por um conjunto de relatos que nos intrigaram: nos idos da década de 1970, Mãe Cacilda (a fundadora do terreiro de umbanda que ainda existe na comunidade) ganhou notoriedade em decorrência dos rituais mediúnicos e das cirurgias espirituais que conduzia. Desse modo, em função da fama de Mãe Cacilda, o território passou a receber um significativo fluxo de pessoas interessadas em participar dos rituais que ocorriam no terreiro; pessoas essas provenientes da região de Corumbá e até de outros estados, como São Paulo, Rio de Janeiro, Mato Grosso e Minas Gerais, que normalmente dirigiam-se à comunidade por meio de caravanas. Nesse ínterim, a perspectiva do turismo religioso, calcado nesse contingente de pessoas que se dirigiam até Corumbá para participar de atividades no terreiro, está entranhada na história a na própria gênese da comunidade quilombola de Maria Theodora.

Após o falecimento de Mãe Cacilda, nos idos do ano 2000, o terreiro perdeu boa parte da fama. Atualmente, são os filhos e netos de Mãe Cacilda que conduzem as atividades no terreiro. As pessoas que ainda o frequentam são os quilombolas que residem em Maria Theodora (a grande maioria deles descendente direta e admiradora dos feitos de Mãe Cacilda), além de moradores de Corumbá e pessoas provenientes da Bolívia (Corumbá faz fronteira com a cidade boliviana de Porto Quijarro).

Nos diálogos e interações com os quilombolas de Maria Theodora, foi possível perceber que seus moradores são vistos, pela sociedade local, a partir do estigma do medo e da repulsa, principalmente em função de professarem, abertamente, a religião da umbanda.

As residências que circundam a comunidade são moradias de alto padrão, bem ornamentadas, muito fechadas e com muros significativamente altos - o que contrasta com a realidade da comunidade, eminentemente simples, com residências muito humildes, cercadas de pequenas estacas de madeira reaproveitada. Os muros altos, além da cerca elétrica e do sistema de monitoramento nas residências que circundam a comunidade, revelam uma tentativa dos moradores dessas residências de se isolarem da comunidade quilombola e dos sujeitos que nela residem.

Segundo os moradores da comunidade, eles mesmos sentem que são vítimas de manifestações de racismo, uma vez que a vizinhança e a própria cidade de Corumbá não os assimilam, com tranquilidade, como quilombolas e, desse modo, não estabelecem 
interações mais francas, efetivas e respeitosas com a comunidade. Ainda de acordo com os quilombolas de Maria Theodora, as manifestações de racismo que recaem sobre eles decorrem do seu pertencimento racial e do fato de professarem, de modo público, uma religiosidade de matriz afro-brasileira.

Outro aspecto paradigmático: o terreiro da comunidade localiza-se em uma construção de alvenaria muito simples e pequena, dotada de apenas uma única porta de ferro. Logo ao transpor a porta, o visitante se depara com um local ornamentado de forma simples, com duas pequenas janelas, à esquerda de quem entra, conforme é possível observar na Figura 2. O que chama a atenção é o fato de que, "colada" a essas duas janelas, há uma parede enorme de uma residência, que fez com que o espaço do terreiro ficasse significativamente abafado e quente, o que é um problema, sobretudo na época do verão, período no qual a cidade de Corumbá convive com temperaturas que facilmente ultrapassam os 40 graus.

Segundo os quilombolas de Maria Theodora, logo quando o muro em questão começou a ser construído, houve a preocupação em dialogar com os proprietários da residência, para que fossem explicitadas as consequências aos frequentadores do terreiro referentes à construção do muro, mas os proprietários da

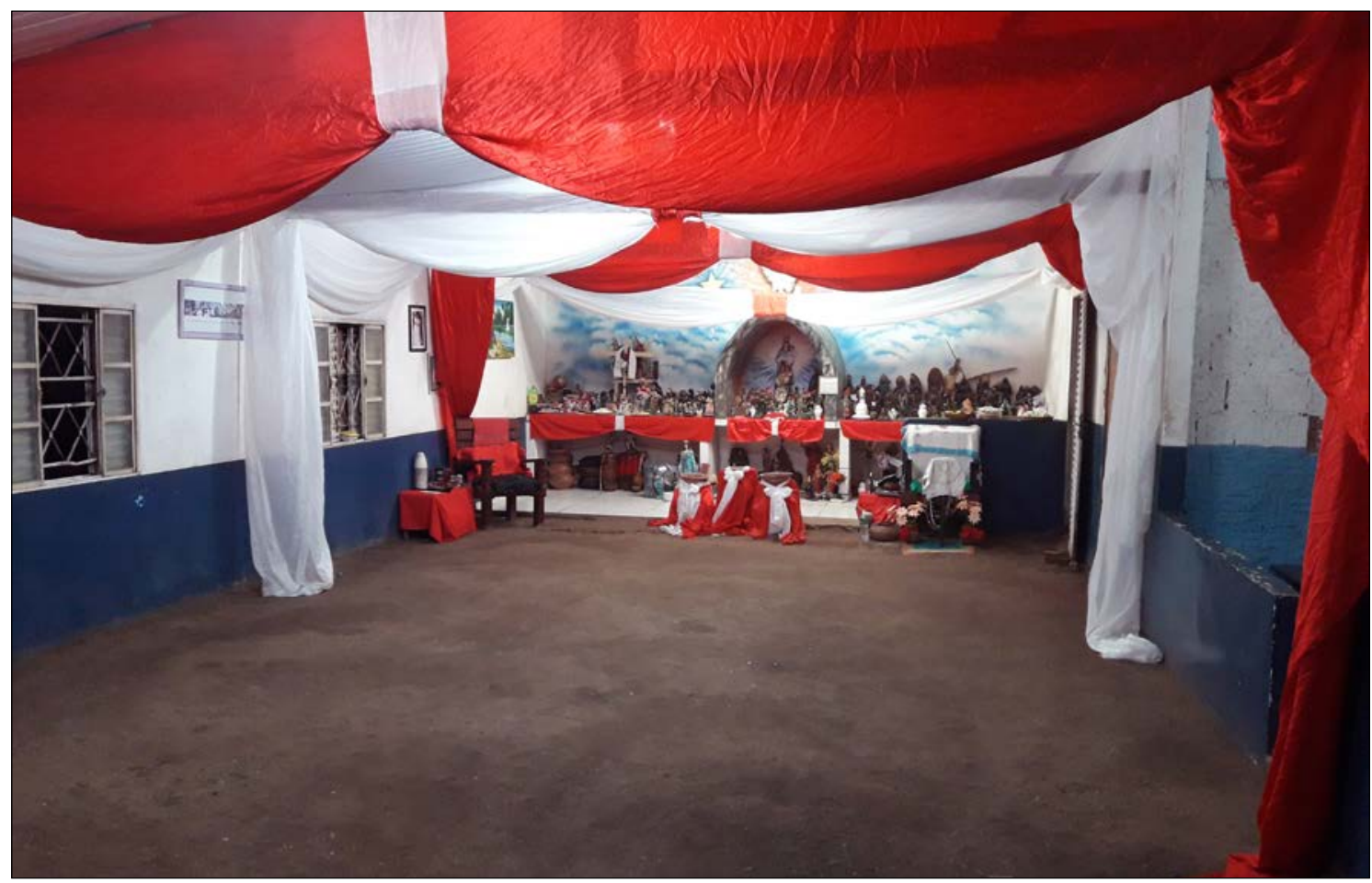

Figura 2 - Detalhes do terreiro localizado na comunidade de Maria Theodora. Foto: Dyego de Oliveira Arruda (2020). 
residência mostraram-se irredutíveis e pouco se dispuseram a dialogar com os quilombolas. Ademais, há uma contenda em torno do local em que o muro foi feito, uma vez que, segundo os quilombolas, parte da área construída da residência encontra-se em um espaço que, por direito, pertence à comunidade. Cientes dessa questão, os quilombolas organizaram-se e protocolaram uma denúncia, ainda na época em que a residência estava em construção, junto à prefeitura de Corumbá e aos demais órgãos competentes. Porém, não houve sucesso nessa empreitada.

Um último aspecto a ser abordado é a temática das oferendas, muito comuns em determinados rituais. A prefeitura de Corumbá, numa tentativa de "ordenar" este aspecto, reservou uma área para que os terreiros que existem no município pudessem realizar as oferendas, em uma localidade que é, no entanto, muito afastada do centro da cidade e de difícil acesso, o que torna complexo e dispendioso o deslocamento das pessoas, sobretudo daquelas mais humildes, tais como a maioria dos frequentadores do terreiro em Maria Theodora.

Vale ainda salientar que, segundo os quilombolas, eles próprios e os demais frequentadores do terreiro carregam, em Corumbá, o estigma eminentemente racista de serem "macumbeiros", protagonistas de "trabalhos do mal", o que reforça os estratagemas que têm como escopo o sentido racista do isolamento em relação à comunidade, vista como permanente fonte de temor e receio.

\section{CONSIDERAÇÕES FINAIS}

Em suma, o quadro de racismo contra as comunidades quilombolas do Mato Grosso do Sul, seja institucional seja religioso, tem como consequência a estigmatização, o isolamento, a necessidade de ressignificar as manifestações culturais e simbólicas, além de tornar precária e inviável a própria vida dos sujeitos nesses territórios. Nesse sentido, restou evidente que a sociedade contemporânea e o próprio aparato de Estado ainda consideram (tal como historicamente sempre foi considerado) os corpos negros e quilombolas enquanto uma subespécie, tal como se fossem sujeitos condenados a viver sob permanente opressão, a ponto de serem compulsoriamente obrigados a renunciar a sua história, cultura, subjetividade e quiçá até a própria vida, conforme nos lembrou o intelectual Frantz Fanon (2005).

Os resultados decorrentes dos diálogos que estabelecemos com os quilombolas do Mato Grosso do Sul nos mostraram que o racismo institucional, em específico, faz com que as 
comunidades não tenham acesso a serviços básicos (como água encanada e luz elétrica), além de cercar de insegurança a relação dos sujeitos com o próprio território que historicamente ocuparam, uma vez que os processos de regularização fundiária das comunidades quilombolas têm sido significativamente morosos. Quando os quilombolas ousam romper as amarras do silêncio e da opressão para, desse modo, denunciar o quadro de precariedade nas comunidades em que vivem, percebese que o racismo institucional, que também impera na estrutura de poder do judiciário e do Ministério Público, logo trata de aplacar, com doses maciças de morosidade e negligência, a atitude e iniciativa dos sujeitos quilombolas em reivindicar aquilo que é básico e de direito das comunidades.

Foi possível perceber que o racismo religioso, por seu turno, impele as comunidades a renunciarem elementos de sua história e cultura, não raro por intermédio de uma adesão compulsória às manifestações religiosas eurocêntricas e brancas. No caso das comunidades que insistem em, publicamente, professar uma fé de matriz afro-brasileira, percebe-se que o racismo religioso logo trata de estigmatizar essas manifestações, vistas como "macumba" e, portanto, dignas de repulsa e medo.

Ao longo das nossas pesquisas de campo, foi possível compreender que as narrativas dos sujeitos quilombolas são vozes subalternizadas, historicamente silenciadas e oprimidas pela lógica colonialista, racista e patriarcal, tal como nos pontuou a intelectual indiana Gayatri Spivak (2010). Nas circunstâncias em que as vozes historicamente silenciadas dos quilombolas ecoam, fica evidenciado um conjunto de dispositivos que corroboram a condição de opressão sob a qual subsistem os sujeitos negros e quilombolas, que são impelidos a viver de forma precária.

O Estado, enquanto ente regulador da sociedade, ao invés de permitir que a vida dos sujeitos negros e quilombolas seja viável, empreende mecanismos que fazem com que a existência dessas pessoas seja precária. Temos a evidenciação do Estado necropolítico de que fala Achille Mbembe (2018), que se esquiva do seu dever de promover a devida regulação fundiária dos territórios quilombolas, ao passo em que também é negligente com a obrigação de oferecer um conjunto mínimo de serviços públicos que permita a viabilidade da vida nessas áreas.

Ademais, constatou-se que os princípios morais e éticos incutidos pelas religiões 
eurocêntricas e brancas fazem com que a comunidade seja empurrada para o limbo do silêncio e da opressão, uma vez que, como dito, os moradores são forçados a renunciar uma série de crenças, tradições e comportamentos histórica e culturalmente determinados.

Portanto, nos pareceu evidente, ao longo das pesquisas e reflexões junto aos territórios quilombolas sul-mato-grossenses, que as múltiplas manifestações de racismo fazem com que os sujeitos subsistam na precariedade e no silêncio. Agora, uma pergunta que nos cumpre fazer, nesse momento, é: como fazer para (re) significar esse quadro, de tal modo que a vida e as vozes nos quilombos ecoem?

Entendemos, tal como nos lembra a filósofa Djamila Ribeiro (2019), que é preciso amplificar a voz dos sujeitos negros aquilombados, reconhecendo os territórios quilombolas enquanto espaços de potência, nos quais podem emergir novas sociabilidades, epistemes criativas, conhecimentos socialmente relevantes, além de múltiplas formas de estar no mundo que façam com que a vida nos quilombos seja possível e viável.

Ademais, acreditamos que é indispensável ter negros e quilombolas em espaços de saber, de poder e de agência nas instituições públicas e privadas, tendo como escopo permitir com que esses sujeitos sejam artífices do processo de ressignificação das práticas historicamente racistas das instituições, sobretudo daquelas que atuam em nome da causa pública. Nesse sentido, vale, aqui, uma menção à imprescindibilidade das políticas e estratégias de ações afirmativas, que justamente possuem o propósito de permitir que os sujeitos historicamente subalternizados ocupem espaços de poder e de agência nas instituições.

Por fim, vale frisar a necessidade de que os vários segmentos da sociedade - o que inclui os movimentos sociais, as instituições públicas e privadas, as empresas, além da universidade e dos grupos de pesquisa - sejam agentes ativos no combate ao racismo e às diversas formas de intolerância, que são, conforme se constatou neste artigo, eminentemente deletérias e destruidoras de vidas e subjetividades.

\section{AGRADECIMENTOS}

Os/a autores/autora agradecem à Universidade Federal de Mato Grosso do Sul (UFMS) e ao Centro Federal de Educação Tecnológica Celso Suckow da Fonseca (CEFET/ $\mathrm{RJ})$, que forneceram apoio institucional para a realização da pesquisa que sustentou as reflexões sumarizadas ao longo deste artigo. Todas as análises conduzidas ao longo do material são de inteira responsabilidade dos/da autores/autora. 


\section{REFERÊNCIAS}

Almeida, S. 2019. Racismo estrutural. São Paulo: Pólen.

Arruda, D. O., e J. P. Gonçalves. 2020. Limites e possibilidades no desenvolvimento de estratégias de Turismo de Base Comunitária em um território quilombola. Interações - Revista Internacional de Desenvolvimento Local 21:107-123. DOI: https://doi.org/10.20435/inter.v21i1.1968

Batista, W. M. 2018. A inferiorização dos negros a partir do racismo estrutural. Revista Direito e Práxis 9(4):2581-2589. DOI: https://doi.org/10.1590/2179-8966/2018/36867

Brasil. 2003. Decreto n. 4.887, de 20 de novembro de 2003. Regulamenta o procedimento para identificação, reconhecimento, delimitação, demarcação e titulação das terras ocupadas por remanescentes das comunidades dos quilombos. Disponível em: http://www.planalto.gov.br/ccivil_03/decreto/2003/ D4887.htm. Acesso em: 27 jan. 2020.

Césaire, A. 1978. Discurso sobre o colonialismo. 1. ed. Lisboa: Sá da Costa Editora.

Coordenação Nacional de Articulação das Comunidades Negras Rurais Quilombolas (CONAQ). 2018. Racismo e violência contra quilombolas no Brasil. Relatório Técnico. Curitiba: Terra de Direitos.

Davis, A. 2016. Mulheres, raça e classe. São Paulo: Boitempo.

Fanon, F. 2005. Os condenados da terra. Juiz de Fora: Ed. UFJF.

Fiabani, A. 2008. Os novos quilombos: luta pela terra e afirmação étnica no Brasil (1988-2008). Tese de doutorado, Departamento de História, Universidade do Vale do Rio dos Sinos, São Leopoldo, Brasil.

Filho, D. S., e G. I. Germani. 2014. A identidade política e social quilombola no Brasil do século XXI. Revista da ABPN 6:78-101. 
Fonseca, D. P. R., e S. M. Giacomini. 2013. Presença do axé: mapeando terreiros no Rio de faneiro. Rio de Janeiro: Ed. PUC-Rio.

Fonseca, I. F. 2015. Inclusão política e racismo institucional: reflexões sobre o Programa de Combate ao Racismo Institucional e sobre o Conselho Nacional de Promoção da Igualdade Racial. Planejamento e Políticas Públicas - PPP 45:329-345.

Gontijo, F., B. Carvalho, e I. Erick. 2016. As experiências da diversidade sexual e de gênero em quilombos do Nordeste e do Norte do Brasil: para início de conversa. Amazônica: Revista de Antropologia 8(1):6289. DOI: http://dx.doi.org/10.18542/amazonica.v8i1.4725

Grosfoguel, R. 2013. The structure of knowledge in westernized universities: epistemic racism/sexism and the four genocides/epistemicides of the long $16^{\text {th }}$ century. Human Architecture: Fournal of the Sociology of Self-Knowledge 11(1):73-90.

Hesse, B. 2004. Im/plausible deniability: racism's conceptual double bind. Social Identities: fournal for the Study of Race, Nation and Culture 10(1):9-29. DOI: https://doi.org/10.1080/1350463042000190976

Kilomba, G. 2019. Memórias da plantação: episódios de racismo cotidiano. Rio de Janeiro: Cobogó.

Leandro, M. E., e L. B. Sanfilippo. 2018. Deus e o diabo na prateleira do mercado: reflexões e narrativas de um racismo religioso vigente. Revista Periferia 10(1):89-99. DOI: https://doi.org/10.12957/ periferia.2018.31449

Leite, I. B. 2010. Humanidades insurgentes: conflitos e criminalização dos quilombos, in Territórios quilombolas e conflitos. Editado por A. W. B Almeida, pp. 17-40. Manaus: UEA Edições.

Mbembe, A. 2018. Necropolítica: biopoder, soberania, estado de exceção, política da morte. São Paulo: N-1 Edições. 
Moreira, A. J. 2019. Racismo recreativo. São Paulo: Pólen.

Nascimento, A. 2019. O quilombismo: documentos de uma militância Pan-Africanista. 3. ed. Rio de Janeiro: Ipeafro.

Oliveira, B. C. (Org.). 2013. Histórias que (re)contam história: análise do povoamento, colonização e reforma agrária do sul de Mato Grosso do Sul. Dourados: Ed. UFGD.

Ribeiro, D. 2019. Lugar de fala. São Paulo: Pólen.

Russo, K., e A. Almeida. 2016. Yalorixás e educação: discutindo o ensino religioso nas escolas. Cadernos de Pesquisa 46(160): 466-483. DOI: http://dx.doi.org/10.1590/198053143305

Schmitt, A., M. C. Turatti, e M. Carvalho. 2002. A atualização do conceito de quilombo: identidade e território nas definições teóricas. Ambiente \& Sociedade (10): 129-136. DOI: https://doi.org/10.1590/S1414-753X2002000100008

Schucman, L. V. 2014. Sim, nós somos racistas: estudo psicossocial da branquitude paulistana. Psicologia \& Sociedade 26(1):83-94. DOI: https://doi.org/10.1590/S0102-71822014000100010

Souzas, R. 2015. Liberdade, violência, racismo e discriminação: narrativas de mulheres negras e quilombolas da mesorregião Centro-Sul da Bahia/Brasil. Revista da ABPN 7(16):89-102.

Spivak, G. 2010. Pode o subalterno falar? Belo Horizonte: Ed. UFMG.

Urquiza, A., e L. Santos. 2017. Regularização fundiária de comunidades quilombolas em Mato Grosso do Sul. Revista Brasileira de Políticas Públicas 7(2):231-247. DOI: https://doi.org/10.5102/rbpp.v7i2.4753

Werneck, J. 2016. Racismo institucional e saúde da população negra. Saúde e Sociedade 25(3):535-549. DOI: https://doi.org/10.1590/s0104-129020162610 
William, R. 2019. Apropriação cultural. São Paulo: Pólen.

Zamora, M. H. R. N. 2012. Desigualdade racial, racismo e seus efeitos. Fractal: Revista de Psicologia 24(3):563-578. DOI: https://doi.org/10.1590/S1984-02922012000300009 